\title{
PRODUÇÃO DE CARVÃO VEGETAL DE CASCA DE BARU (Dipteryx alata) UTILIZANDO CÉLULAS DE CARBONIZAÇÃO
}

\author{
Ailton Teixeira do Vale ${ }^{1}$, Leandro Borges Olsen ${ }^{2}$ \\ ${ }^{1}$ Eng. Florestal, Dr., Depto. de Engenharia Florestal, UnB, Brasília, DF, Brasil - ailton.vale@gmail.com \\ ${ }^{2}$ Acadêmico de Engenharia Florestal, UnB, Brasília, DF, Brasil - Ibounb@gmail.com \\ Recebido para publicação: 18/04/2011 - Aceito para publicação: 07/02/2013
}

\begin{abstract}
Resumo
Em Pirenópolis, GO, o extrativismo do baru (Dipteryx alata Vog.) é comum entre os pequenos produtores rurais. Organizações não governamentais têm desenvolvido projetos de comercialização da amêndoa para aumentar a renda familiar. O extrativismo gera uma grande quantidade de resíduos na forma de casca. A casca descartada no meio ambiente contribui para a poluição ambiental. No entanto, a transformação em carvão vegetal agrega valor, tornando-a um produto comercializável para churrasco. O objetivo deste trabalho foi avaliar um sistema de produção de carvão de casca baru em células de carbonização. Na carbonização, utilizou-se um forno metálico envolto em cápsula de alvenaria com fonte de calor externa. A casca de baru utilizada foi coletada em Pirenópolis, e o experimento foi conduzido na Universidade de Brasília. Foram testados dois tratamentos, carbonização em 7,5 h e em 9,5 h. Para todas as variáveis estudadas, não foi encontrada diferença significativa entre os tratamentos, optando-se pela carbonização em 7,5 h. A carbonização realizada em 7,5 horas gerou rendimento em carvão vegetal acima de $32 \%$, com qualidades do carvão vegetal semelhantes àquelas encontradas na literatura. Portanto, o sistema de produção de carvão vegetal de baru utilizando células de carbonizações mostrou-se eficiente e pode ser utilizado em substituição a outros sistemas.
\end{abstract}

Palavras-chave: Células de carbonização; casca; Dipteryx alata; carvão.

\begin{abstract}
Charcoal production of bark of baru (Dipteryx alata) using carbonization cells. In Pirenópolis - GO, extraction of baru (Dipteryx alata Vog.) is common among small farmers. Non-governmental organizations have developed projects for the marketing of almonds to increase family income. The extraction generates a lot of waste in the form of bark. The bark discarded in the environment contributes to environmental pollution. However, the transformation into charcoal adds value by making it a marketable product for barbecue. The objective of this study was to evaluate a production system of charcoal from baru bark in carbonization cells. For the carbonization it was used a metallic furnace encased in brick with external heat source. The bark came from Pirinópolis and the experiment was developed at the University of Brasilia. Two treatments were tested, carbonization at $7.5 \mathrm{~h}$ and $9.5 \mathrm{~h}$. For all studied variables it was not found significant differences between treatments, then the option is carbonization at $7.5 \mathrm{~h}$. The carbonizations were performed in 7.5 hours, producing charcoal yield above $32 \%$ with qualities similar to those found in the literature. Therefore, the production system of charcoal from "baru" bark using carbonization cells was efficient and can be used instead of other systems.

Keywords: Cell carbonization; bark; Dipteryx alata; charcoal.
\end{abstract}

\section{INTRODUÇÃO}

A carbonização é a transformação térmica da madeira na presença controlada de oxigênio ou ar, liberando duas frações, uma gasosa e outra sólida (VALENTE; LELLES, 1986), ocorrendo uma saída de oxigênio e uma concentração de carbono na massa de carvão, com consequente aumento no poder energético, em relação ao material de origem.

A produção desse recurso energético é um dos principais meios de geração de energia renovável no Brasil, implicando o consumo de 13,1\% do consumo energético nacional a partir da madeira (Brasil, 
2012). No Brasil, a produção de carvão vegetal é realizada, basicamente, com material lenhoso obtido de florestas nativas e florestas plantadas (NOGUEIRA; LORA, 2003).

Uma terceira alternativa para a produção de carvão vegetal é o aproveitamento de resíduo agroflorestal proveniente do processamento de toras em serraria, ou da colheita florestal, e do extrativismo vegetal, ou de culturas agrícolas, principalmente cascas, que em alguns casos pode atender a demanda por carvão em siderurgias, como no Maranhão, com a carbonização de casca de coco de babaçu.

Um resíduo pode ser definido como toda substância, material, ou produto que sobra de um processo de produção, exploração, transformação ou de utilização, sendo normalmente destinado ao abandono (QUIRINO, 2002). A utilização racional e eficiente dos recursos de biomassa, mediante o emprego de tecnologias modernas e a utilização de resíduos, é uma alternativa viável para produção de energia (BENZO; LUENGO, 1998). Também a utilização de resíduos para a geração de energia, na forma de carvão vegetal, além de ser uma prática ambientalmente correta, pode agregar valor a atividades já desenvolvidas (LISBOA, 2003), contribuindo para o bem-estar ambiental e social de pequenas comunidades que retiram parte de seu sustento do extrativismo vegetal.

Em algumas regiões, como Pirenópolis (GO), o extrativismo do baru (Dipteryx alata Vog.) é muito comum entre os pequenos produtores rurais e organizações não governamentais (ONGs), que têm desenvolvido trabalhos no sentido de aumentar a renda familiar a partir da comercialização da amêndoa do fruto, produzindo, com isso, uma quantidade significativa de resíduos na forma de casca.

A espécie Dipteryx alata pertence à família Fabaceae, subfamília Papilonoideae, com ocorrência no cerrado sensu stricto, cerradão mesotrófico e matas mesofíticas (ALMEIDA et al., 1998). Considerada uma planta heliófita de distribuição irregular, podendo ocorrer em grandes agrupamentos, pode ser encontrada em diversos estados do Brasil, desde Amazonas e Goiás até São Paulo (ALMEIDA et al., 1998).

Carvalho et al. (2006), carbonizando casca de baru diretamente em forno metálico, sem cápsula de alvenaria e sem câmara de combustão externa, construído também com latão de 200 litros, encontraram rendimento em carvão vegetal da ordem de $31 \%$ em um tempo total de $8 \mathrm{~h} 40 \mathrm{~min}$.

Cemin (2009) desenvolveu um sistema de carbonização com forno metálico envolto em cápsula de alvenaria e com câmara de combustão externa para carbonização de madeira de eucalipto. Esse mesmo sistema, ao ser utilizado para a carbonização de casca de baru, não logrou êxito, em função da dificuldade de circulação dos gases, o que motivou a inclusão de células metálicas de carbonização.

Nesse sentido, o objetivo principal deste trabalho foi avaliar a produção de carvão de casca de baru em sistema composto por células metálicas dispostas dentro de forno metálico envolto em cápsula de alvenaria acoplada a uma câmara de combustão externa, considerando dois tratamentos, 7,5 e 9,5 h. Os objetivos secundários foram determinar o rendimento da carbonização e qualificar o carvão vegetal produzido.

\section{MATERIAIS E MÉTODO}

Para este estudo, a casca do baru utilizada na carbonização foi obtida em uma cooperativa de coletores e vendedores da semente desse fruto na cidade de Pirenópolis, GO. Essa região está inserida no Cerrado e possui clima característico das savanas, que, pela classificação de Köppen, é o Aw. O sistema de carbonização foi construído na Fazenda Água Limpa - FAL/UnB, situada a $30 \mathrm{~km}$ da cidade de Brasília (sede: $15^{\circ} 57^{\prime} \mathrm{S}$ e $47^{\circ} 56^{\prime} \mathrm{W}$ ).

O forno metálico envolto em cápsula de alvenaria com câmara de combustão externa desenvolvido por Cemin (2010) contém: figura 1A - forno metálico construído a partir da reciclagem de um tambor de óleo de 200 litros, com $60 \mathrm{~cm}$ de diâmetro e $86 \mathrm{~cm}$ de altura, cuja tampa foi transformada em grelha (perfurada para permitir a entrada de calor), contendo uma saída de gases no centro; figura 1B estrutura de alvenaria (unidade isolante), construída com tijolos maciços e revestida com argamassa (terra e água), que consiste de uma base contendo a fornalha ou câmara de combustão externa (utilizada para produção de calor para a carbonização) e sobre esta base uma cápsula cilíndrica (onde é inserido o forno metálico).

No processo de carbonização, o forno metálico, contendo as células metálicas de carbonização carregadas de casca de baru, é içado (Figura 1A) e inserido dentro da cápsula de alvenaria, de tal forma que a saída de gases da grelha seja acoplada a uma chaminé, que, além de ser o escape dos gases liberados no processo, serve para aumentar o empuxo dos gases para fora do sistema. Em seguida, a cápsula é fechada com uma tampa de metal e vedada com barro, para evitar o vazamento de gases. 
Para controle da temperatura de carbonização, um termopar de liga de níquel-cromo acoplado a um termômetro digital foi introduzido perpendicularmente ao forno, através de um orifício.

As células metálicas de carbonização são estruturas com seção quadrada e com altura igual à do forno metálico, sendo compostas por armações de vergalhão, envoltas por uma tela de arame, com as seguintes dimensões: 3 células com $86 \mathrm{~cm}$ de altura e $12 \mathrm{~cm}$ de aresta e outras três com $86 \mathrm{~cm}$ de altura e $15 \mathrm{~cm}$ de aresta (Figura 1C).

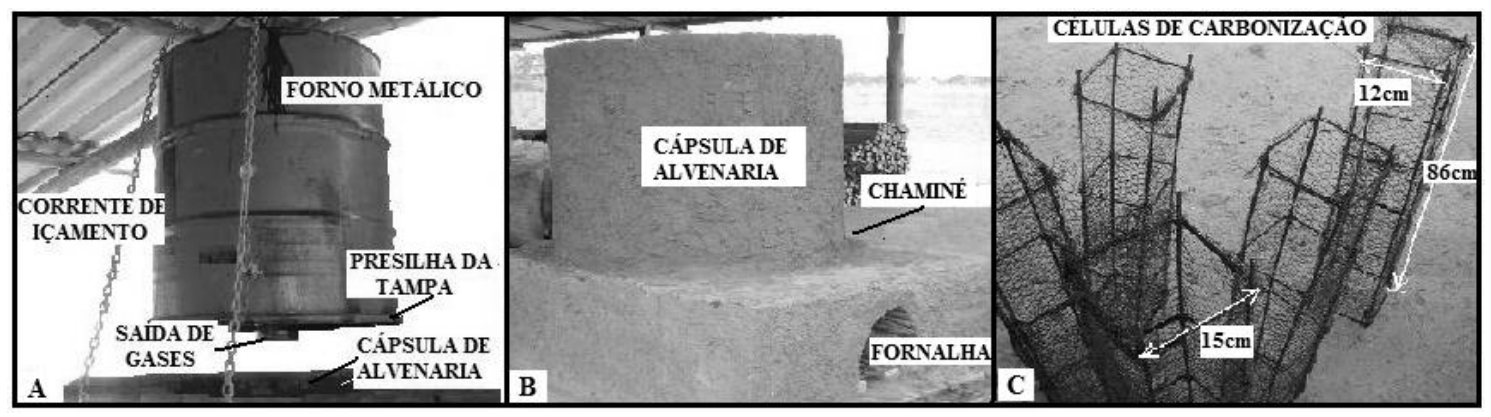

Figura 1. A: Forno metálico suspenso; B: Cápsula e fornalha; C: Células de carbonização.

Figure 1. A: Metallic oven suspended; B: Capsule and furnace; C: Carbonization cells.

Foram utilizados dois tratamentos equivalentes ao tempo de carbonização com três repetições cada: tratamento 1 - 07:30 horas; e tratamento 2 - 09:30 horas, para avaliar o sistema de carbonização em células metálicas e também a possibilidade de redução do tempo de carbonização. Lenha de eucalipto foi utilizada como combustível na fornalha. Para cada carbonização, foram tomadas a massa da carga de casca de baru, na condição úmida, e a massa do carvão vegetal seco a $0 \%$ de umidade. De cada carga de casca de baru foi retirada uma amostra para determinação do teor de umidade.

\section{Análises realizadas}

O teor de umidade foi determinado segundo a norma NBR 7190/1997 e Vital (1984). O rendimento em carvão vegetal foi calculado pela relação percentual entre a massa seca de carvão vegetal e a massa seca da casca de baru. A densidade aparente do carvão vegetal foi determinada segundo a norma ABNT 9195/85, e para a determinação da densidade verdadeira do carvão vegetal utilizou-se a norma ASTM D-167-73 "Specific Gravity and Porosity of Lump Coke", segundo adaptação de Oliveira et al. (1982) para carvão vegetal. De posse da densidade aparente e da densidade verdadeira, determinou-se a porosidade do carvão vegetal conforme a norma ABNT 9165/85. A densidade a granel da casca in natura e do carvão vegetal foi determinada a partir da massa contida em um recipiente com volume de $4.860 \mathrm{~cm}^{3}$, medida em balança digital Micronal modelo B1600, com sensibilidade de $0,01 \mathrm{~g}$. A análise imediata seguiu a norma ABNT 8112/86, e o poder calorífico superior foi estimado segundo Vale et al. (2002), com auxílio da equação 1.

$$
P C S=8239,47-32,95 *(M V) \quad \text { Equação } 1
$$

Em que: $\mathrm{PCS}=$ poder calorífico superior $(\mathrm{kcal} / \mathrm{kg}) ; \mathrm{MV}=$ teor de materiais voláteis $(\%)$.

A análise estatística foi realizada utilizando ANOVA, conforme o software BioEstat 5.0 (AYRES et al., 2007).

\section{RESULTADOS E DISCUSSÃO}

\section{Carregamento e colocação do forno metálico na cápsula}

O processo de produção de carvão vegetal utilizando as células de carbonização inicia com a pesagem da casca e carregamento das células (Figura 2A). Em seguida, as células carregadas são 
dispostas dentro do forno metálico conforme a figura $2 \mathrm{~B}$, e então se coloca a grelha. O forno metálico é içado com a grelha voltada para baixo e colocado dentro da cápsula de alvenaria (Figura 2C), com a saída de gases (Figura 2D) sendo encaixada na chaminé na base interna da cápsula (Figura 2E). Na sequência, a cápsula de alvenaria é fechada com uma tampa metálica e vedada com argamassa (Figura 2F), para início da carbonização.

\section{Carbonização e descarregamento do forno}

O processo de carbonização é composto de três fases distintas: secagem, pirólise (reações exotérmicas) e carbonização propriamente dita. Para promover a secagem da casca, que possui de 15 a $16 \%$ de sua massa seca constituída de água higroscópica (Tabela 1), foi necessária a combustão de 4 a $6 \mathrm{~kg}$ de lenha dentro da fornalha (câmara de combustão externa) (Figura 3A), durante, em média, $2 \mathrm{~h}$, para o início das reações exotérmicas e autossustentação térmica do processo, verificado pela grande quantidade de fumaça densa que saía da chaminé. Nesse ponto, a fornalha é fechada, deixando apenas uma abertura para entrada de ar, suficiente para manter a carbonização (Figura 3B). Terminada a carbonização, que era definida pela diminuição drástica de fumaça na chaminé, o forno era totalmente vedado (Figura 3C) e deixado para resfriamento de um dia para o outro (com a opção de içar o forno ainda quente imediatamente após a carbonização e colocá-lo sobre um banco de areia, o que aceleraria o resfriamento). Após o resfriamento, o forno metálico contendo o carvão foi içado (Figura 3D) e aberto, retirando-se as células de carbonização contendo o carvão (Figura 3E). As células foram descarregadas e o carvão ensacado (Figura 3F).

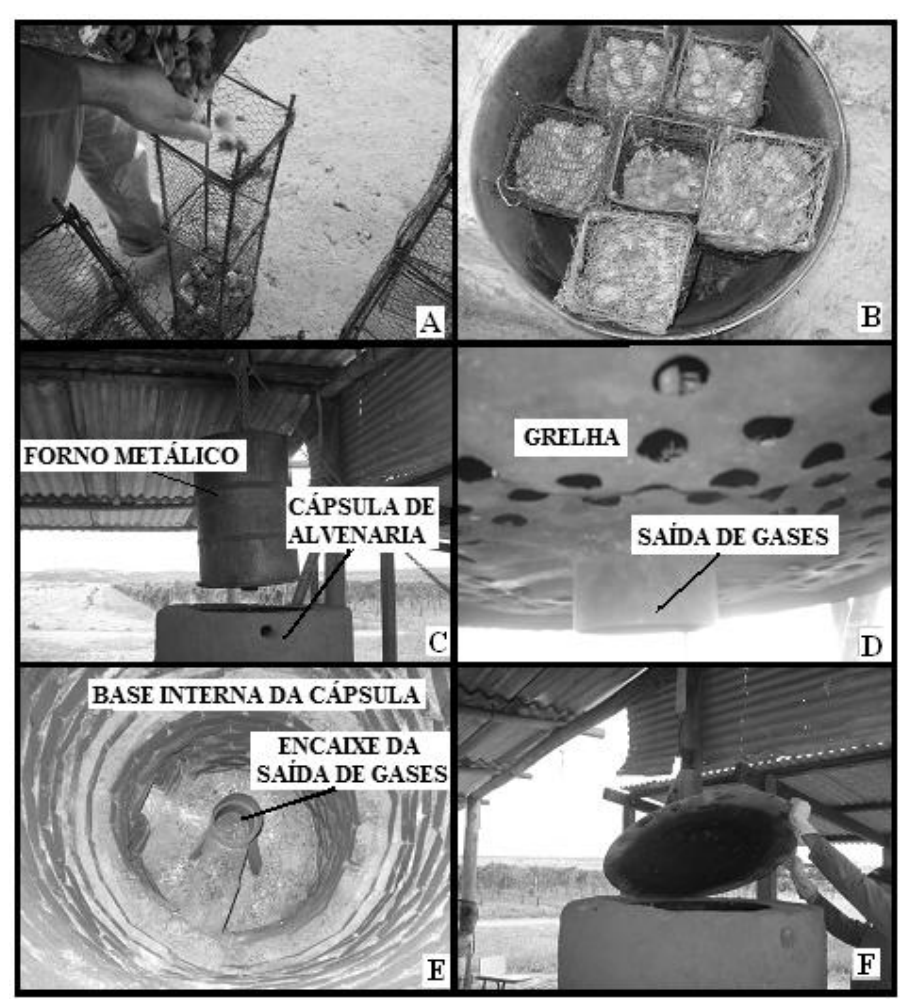

Figura 2. Sistema de carbonização com células.

Figure 2. Carbonization system with cells.

\section{Rendimento e qualificação do carvão} tratamentos.

Na tabela 1, estão os valores médios encontrados para as variáveis estudadas nos dois 


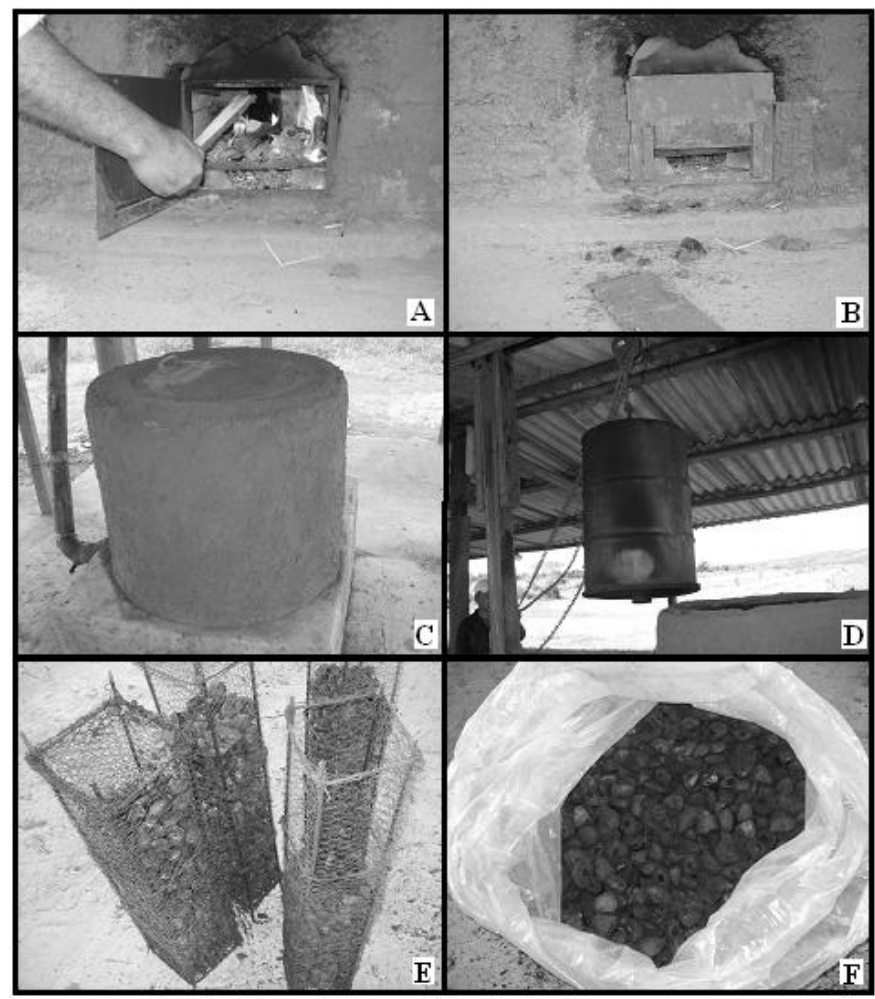

Figura 3. Combustão de lenha na fornalha e retirada do carvão vegetal.

Figure 3. Wood combustion in the furnace and charcoal removing.

Tabela 1. Valores médios de densidade do granel da casca (Dgcas) e do carvão da casca (Dgcar) de baru e características do carvão vegetal: densidade aparente (Da), densidade verdadeira (Dv), porosidade $(\mathrm{Po})$, cinzas $(\mathrm{CZ})$, material volátil $(\mathrm{MV})$, carbono fixo $(\mathrm{CF})$, poder calorífico superior estimado (PCS) e rendimento (\%).

Table 1. Mean values of bulk density of the bark (Dgcas) and bulk density of the bark charcoal (Dgcar) and charcoal characteristics: apparent density (Da), true density (Dv), porosity (Po), ash (CZ ), volatile matter (VM), fixed carbon (FC), combustion heat (PCS) and yield gravimetric (\%).

\begin{tabular}{|c|c|c|c|c|c|}
\hline Tratamento & $\begin{array}{c}\text { Dgcas } \\
\left(\mathbf{k g} / \mathbf{m}^{3}\right)\end{array}$ & $\begin{array}{c}\text { Dgcar } \\
\left(\mathrm{kg} / \mathbf{m}^{3}\right)\end{array}$ & $\underset{\left(\mathrm{g} / \mathrm{cm}^{3}\right)}{\mathrm{Da}}$ & $\begin{array}{c}\text { Dv } \\
\left(\mathrm{g} / \mathrm{cm}^{3}\right)\end{array}$ & $\begin{array}{c}\text { Po } \\
(\%)\end{array}$ \\
\hline $\mathrm{I}(7,5 \mathrm{~h})$ & 471 & 368 & 0,72 & 1,30 & 44,54 \\
\hline \multirow[t]{2}{*}{ II $(9,5 \mathrm{~h})$} & 482 & 353 & 0,65 & 1,25 & 47,55 \\
\hline & $\begin{array}{l}\mathbf{C Z} \\
(\%) \\
\end{array}$ & $\begin{array}{l}\text { MV } \\
(\%)\end{array}$ & $\begin{array}{l}\text { CF } \\
(\%)\end{array}$ & $\begin{array}{c}\text { PCS } \\
(\text { kcal } / \mathrm{kg})\end{array}$ & $\begin{array}{c}\text { Rendimento } \\
(\%)\end{array}$ \\
\hline $\mathrm{I}(7,5 \mathrm{~h})$ & 4,702 & 34,163 & 61,135 & 6.224 & 32,84 \\
\hline II $(9,5 \mathrm{~h})$ & 4,115 & 29,32 & 66,565 & 6.045 & 30,95 \\
\hline
\end{tabular}

Pela análise de variância da tabela 2, pode-se afirmar que não há diferença significativa entre os tratamentos para nenhuma das variáveis estudadas. Nesse caso, pode-se considerar como condição melhor o tempo de $7,5 \mathrm{~h}$.

A tabela 3 apresenta os valores médios de massa, teor de umidade e rendimento gravimétrico, considerando que o carvão foi pesado imediatamente após a abertura do forno, tendo sido considerado seco a $0 \%$ de umidade. Em média, a produção de tico foi de 5,8 kg. 
Tabela 2. Valores de "F" para as variáveis qualitativas do carvão vegetal: densidade aparente (Da), densidade verdadeira (Dv), porosidade (Po), densidade do granel da casca (Dgcas), densidade do granel do carvão da casca (Dgcar), cinzas (CZ), material volátil (MV), carbono fixo (CF) e poder calorífico superior (PCS).

Table 2. Values of "F" for qualitative variables charcoal: apparent density (Da), true density (Dv), porosity (Po), bulk density of the bark (Dgcas), bulk density of the charcoal (Dgcar), ash (CZ), volatile matter (VM), fixed carbon (FC) and combustion heat (PCS).

\begin{tabular}{|c|c|c|c|c|c|c|c|c|c|c|}
\hline \multirow{2}{*}{ FV } & \multirow{2}{*}{ GL } & \multicolumn{9}{|c|}{ Valores de "F" } \\
\hline & & Da & Dv & Po & Dgcas & Dgcar & $\mathbf{C Z}$ & MV & $\mathbf{C F}$ & PCS \\
\hline Trat. & 1 & \multirow{3}{*}{$0,837^{\mathrm{ns}}$} & \multirow{3}{*}{$2,597^{\mathrm{ns}}$} & \multirow{3}{*}{$0,186^{\text {ns }}$} & \multirow{3}{*}{$2,581^{\mathrm{ns}}$} & \multirow{3}{*}{$1,043^{\mathrm{ns}}$} & \multirow{3}{*}{$3,499^{\text {ns }}$} & \multirow{3}{*}{$1,276^{\mathrm{ns}}$} & \multirow{3}{*}{$1,592^{\mathrm{ns}}$} & \multirow{3}{*}{$1,275^{\mathrm{ns}}$} \\
\hline Res. & 4 & & & & & & & & & \\
\hline Total & 5 & & & & & & & & & \\
\hline
\end{tabular}

Tabela 3. Valores médios das massas, umidade de lenha e casca de Dipterix alata e rendimento gravimétrico.

Table 3. Average mass values, moisture from wood and bark Dipterix alata and gravimetric yield.

\begin{tabular}{|c|c|c|c|c|}
\hline \multirow[b]{2}{*}{ Tempo (h) } & \multicolumn{2}{|c|}{ Massa (kg) } & \multirow{2}{*}{$\begin{array}{l}\text { Umidade } \\
\text { casca }(\%)\end{array}$} & \multirow{2}{*}{$\begin{array}{c}\text { Rendimento } \\
\text { gravimétrico }(\%)\end{array}$} \\
\hline & Casca & Carvão de casca & & \\
\hline 7,5 & 47,67 & 13,67 & 16,06 & 32,84 \\
\hline
\end{tabular}

Os rendimentos foram superiores aos 27,6\% encontrados por Cemin (2010) para a carbonização de Eucalyptus grandis W. Hill. ex Maiden utilizando o mesmo forno, e semelhantes aos 30,7\% encontrados por Brito et al. (1987) quando carbonizaram bambu em forno de laboratório.

A casca de baru é um material de elevada dureza quando comparada com a madeira, motivo pelo qual produz carvões de densidade superior, haja vista o resultado encontrado por Cemin (2010) para densidade aparente de carvão de madeira de Eucalyptus grandis (igual a $0,36 \pm 0,01 \mathrm{~g} / \mathrm{cm}^{3}$ ), que, juntamente com a densidade verdadeira $\left(1,41 \pm 0,03 \mathrm{~g} / \mathrm{cm}^{3}\right)$, possibilitou o cálculo da porosidade em $74,45 \pm 0,55 \%$. A porosidade em torno de $45 \%$ para o carvão de baru indica menor quantidade de espaços vazios no interior do material, portanto maior densidade aparente. Mas quando a comparação é feita com coco de babaçu e de macaúba, os resultados ficam mais próximos, e isso pode ser comprovado pelos resultados encontrados por Silva et al (1986), quando carbonizaram coco de babaçu e de macaúba a $500{ }^{\circ} \mathrm{C}$ em laboratório: densidade aparente, densidade verdadeira e porosidade, respectivamente, de $0,901 \mathrm{~g} / \mathrm{cm}^{3}, 1,5 \mathrm{~g} / \mathrm{cm}^{3}$ e $39,96 \%$ para o babaçu, e de $0,887 \mathrm{~g} / \mathrm{cm}^{3}, 1,37 \mathrm{~g} / \mathrm{cm}^{3}$ e $35,36 \%$ para a macaúba.

Uma característica que diferencia o carvão de casca de baru daquele obtido por madeira é o teor de cinzas, que se apresenta elevado. No entanto, quando comparado com carvão de coco de palmáceas e com o de bambu, os valores são mais próximos. Cemin (2010), trabalhando com carbonização de madeira de eucalipto nas mesmas condições e tipo de forno, encontrou $1,12 \pm 0,3 \%$ para o teor de cinzas, $29,89 \pm 3,49 \%$ para o teor de materiais voláteis e $68,99 \pm 3,58 \%$ para o teor de carbono fixo. Trabalhando com resíduo de palmeiras, endocarpos de macaúba e babaçu, carbonizados em forno de laboratório a $500{ }^{\circ} \mathrm{C}$, SILVA et al. (1986) encontraram, para teores de matérias voláteis, cinzas e carbono fixo, respectivamente, os seguintes resultados: $10,77 \%, 2,49 \%$ e $86,83 \%$ para macaúba, e 9,22\%, 6,03\% e $84,75 \%$ para babaçu. Brito et al. (1986), trabalhando com cinco espécies/variedades de bambu, encontrou em média 5,8\% de teor de cinzas e $85,6 \%$ de carbono fixo.

O poder calorífico representa a quantidade de energia térmica liberada pela combustão total de uma unidade de massa de um material. No trabalho com eucalipto de Cemin (2010), foram encontrados valores médios da ordem de $7.353 \mathrm{kcal} / \mathrm{kg}$ para o carvão, enquanto que para o carvão de resíduo de baru esses valores foram inferiores, em função do alto teor de material volátil e de cinzas. No trabalho com bambu, de Brito et al. (1986), o PCS médio do carvão de cinco espécies/variedades encontrado foi de $7.868 \mathrm{kcal} / \mathrm{kg}$.

O sistema proposto para carbonização de casca de baru mostrou-se perfeitamente adaptado para a produção de carvão a partir desse resíduo. Quanto à qualidade, o carvão de baru mostrou-se superior ao carvão de madeira, comumente comercializado no Brasil para uso em churrasqueiras, quanto a aspectos 
importantes para esse fim, como é o caso da densidade, haja vista a elevada densidade aparente, que possibilita maior tempo de residência do carvão nas churrasqueiras, diminuindo assim o trabalho para manutenção do calor. Dessa forma, tanto o sistema quanto o resíduo podem ser utilizados para agregar valor ao resíduo e possibilitar a melhoria da qualidade de vida de pequenas comunidades.

\section{CONCLUSÃO}

- A carbonização da casca de baru obteve sucesso com o sistema de carbonização usando forno metálico com cápsula de alvenaria e células individuais, apresentando bom rendimento e produzindo carvão de boa qualidade.

- O uso de células individuais permitiu a circulação do ar quente oriundo da câmara de combustão e posteriormente da própria carga de casca de baru.

- A autossustentação térmica do forno, ativada pela liberação de energia exotérmica da própria carga, também funcionou de maneira esperada.

- Esse sistema pode ser aplicado nas propriedades de coletores desse fruto, agregando valor ao resíduo, que via de regra é descartado, com geração de energia de forma sustentável.

\section{REFERÊNCIAS}

ALMEIDA, S. P.; PROENÇA, C. E. B.; SANO, S. M.; RIBEIRO, J. F. Cerrado: espécies vegetais úteis. Planaltina-DF: Embrapa. 1998. 464 p.

ASSOCIAÇÃO BRASILEIRA DE NORMAS TÉCNICAS (ABNT) NBR 8112 - Análise imediata. Rio de Janeiro: ABNT. 2006. 5 p.

. NBR 9165 - Determinação da densidade relativa aparente, relativa verdadeira e porosidade. Rio de Janeiro: ABNT. 2005. 8 p.

AYRES, M.; AYRES, J. R. M.; AYRES, D. L.; SANTOS, A. S. BioEstat 5.0: aplicações estatísticas nas áreas das ciências biológicas e médicas. Belém: Instituto de Desenvolvimento Sustentável Mamirauá IDSM/MCT/CNPq, 5 ed. 364 p. 2007.

BENZO, G.; LUEHGO, C. A. Biomassa com potencial energético adicional aos combustíveis fósseis. In: Congresso Brasileiro de Planejamento Energético, 3, São Paulo. Anais... 1998. p. 133 - 137.

BRASIL - MINISTÉRIO DE MINAS E ENERGIA. Balanço Energético Nacional 2012: Ano base 2011. Empresa de Pesquisa Energética - Rio de Janeiro: EPE, 2012. 282 p.

CARVAlho, R. S.; VAle, A. T. do; DEL MENEZZI, C. H. S.; CARRAZZA, L.; MOTA, C. Desenvolvimento de um forno para carbonização de resíduo do fruto de baru (Dipteryx alata), v. 1, p. 82. In: IV Congresso Florestal Latino-Americano. Mérida, Venezuela. Anais... Médida: Faculdad de Ciências Forestales y Ambientales, 2006.

CEMIM, D. S. Desenvolvimento de um forno para carbonização de resíduos agroflorestais em pequena escala. 63 f. Dissertação (Mestrado em Ciência Florestal) - Departamento de Engenharia Florestal, Faculdade de Tecnologia, Universidade de Brasília, Brasília, DF, 2010.

LISBOA, R. J. Caracterização energética da casca de baru (Dipterys alata Vog.) para produção de carvão vegetal e briquete. 37 p. Projeto final de curso (Graduação em Engenharia Florestal) Departamento de Engenharia Florestal, Universidade de Brasília. Brasília, DF. 2003. (não publicado)

NOGUEIRA, L. A. H.; LORA, E. E. S. Dendroenergia: fundamentos e aplicações. Rio de Janeiro: Interciência, 2 ed. 199 p. 2003.

OLIVEIRA, J. B. O.; GOMES, P. A.; ALMEIDA, M. R. Estudos preliminares de normalização de testes de controle de qualidade de carvão vegetal. In: Carvão vegetal. Fundação Centro Tecnológico de Minas Gerais/CETEC. Belo Horizonte, 1982. v. 1. (Série de publicações técnicas, 6). 
QUIRINO, W. F. Utilização energética de resíduos vegetais. Ministério do Meio Ambiente - MMA, Instituto Brasileiro do Meio Ambiente e dos Recursos Naturais Renováveis - IBAMA, Diretoria de Florestas. Laboratório de Produtos Florestais - LPF. 35 p. 2002. Disponível em: <http://www.mundoflorestal.com.br/arquivos/aproveitamento.pdf/>. Acesso em: 15/06/2012.

SILVA, J. C.; BARRICHELO, L. E. G.; BRITO, J. O. Endocarpo de babaçu e de macaúba comparados a madeira de Eucalyptus grandis para a produção de carvão vegetal. IPEF, São Paulo, SP, n. 34, p. 31 - 34, 1986.

VALE, A. T.; ABREU, V. L. S.; GONÇALEZ, J. C.; COSTA, A. F. Estimativa do poder calorífico do carvão vegetal de madeira de Eucalyptus grandis em função do teor de carbono fixo e do teor de materiais voláteis. Brasil Florestal, Brasília, DF, n. 73, p. 47 - 52, 2002.

VALENTE, A. F.; LELLES, J. G. Carbonização da madeira de Eucalyptus. Informe Agropecuário, Belo Horizonte, n. 141, p. 74 - 79, 1986.

VITAL, B. R. 1984. Métodos de determinação da densidade da madeira. Viçosa: Sociedade de Investigações Florestais, 1984. 21 p. (Boletim Técnico, 1). 